\title{
Pós-Graduação em estudos brasileiros
}

Em novembro de 2006 foi encaminhada à Pró-Reitoria de Pós-Graduação (CPGr) da Universidade de São Paulo a proposta de criação de um programa de pós-graduação stricto sensu, em nível de mestrado, intitulado Culturas e Identidades Brasileiras. Conforme Resolução CoPGr-5433 de 13 de fevereiro de 2008, o Regulamento do Programa foi aprovado. Apresentamos nesta notícia as diretrizes que orientaram a elaboração da proposta e os conteúdos e estrutura geral do programa.

\section{1) Síntese da proposta}

0 Instituto de Estudos Brasileiros é um centro multidisciplinar de educação, pesquisa e documentação sobre a cultura do país. Reúne estudiosos de formação variada que nele oferecem disciplinas de graduação, difusão e extensão e orientam trabalhos de iniciação científica e pós-doutorado. Refletir sobre a sociedade brasileira articulando múltiplas áreas do saber constitui o desafio fundador do IEB, agora renovado na proposta de criação de um programa de pós-graduação que, ao proporcionar uma formação multidisciplinar em estudos brasileiros, possuirá caráter único dentro do universo de programas de pós-graduação atualmente vigentes na Universidade de São Paulo.

0 Regimento do IEB afirma que a Instituição "tem por finalidade a pesquisa da cultura brasileira em seus múltiplos aspectos". Para tanto, deverá:

I - desenvolver métodos e técnicas de investigação em Ciências Humanas, Letras e Artes, assim como realizar, em caráter permanente, pesquisas relacionadas com os estudos brasileiros; II - divulgar os resultados obtidos mediante projetos, palestras, cursos, seminários, intercâmbios, estágios, exposições e publicações;

III - promover cursos de Pós-Graduação nos níveis de Mestrado e Doutorado, disciplinas de Graduação, bem como cursos de Extensão Universitária;

Aí já se vislumbra a necessidade de estruturação de uma pós-graduação de caráter multidisciplinar. É certo que, para chegar ao perfil que o organiza atualmente, o IEB passou por transformações importantes, como, por exemplo, as que resultaram do fato de os pesquisadores de Institutos Especializados da 
USP terem sido recentemente integrados à carreira docente - o que, justamente, possibilitou a diversos desses Institutos constituírem seus programas de pós-graduação. Assim, a iniciativa do Instituto de Estudos Brasileiros, além de obedecer às determinações de seu Regimento, insere-se num quadro institucional que reconhece tais Institutos como unidades universitárias que articulam, obrigatoriamente, ensino, pesquisa e extensão.

O Programa Multidisciplinar Culturas e Identidades Brasileiras tem como objetivos principais a realização de pesquisas e o desenvolvimento de reflexões sobre a sociedade e a cultura brasileiras a partir da perspectiva multidisciplinar, voltando-se particularmente para a análise e a interpretação das inúmeras realidades da América Portuguesa e do Brasil. Para tanto, foi estruturado de modo a que nele se processe um incessante diálogo entre especialistas de áreas diversas, diálogo que alicerçará a formação de professores, pesquisadores e especialistas aptos a intervir nos debates contemporâneos - os quais, como se sabe, exigem uma postura crítica, dinâmica e participativa, em que não cabem compartimentos rigidamente estabelecidos. Com isso, pretende-se reforçar a capacidade da universidade de construir e enfrentar questões concernentes ao Brasil do presente e do futuro, bem como aos pontos de permanência e ruptura de nossa sociedade e cultura em relação à diversidade de heranças, em múltiplas instâncias, que marcaram sua formação.

De forma geral, preparar o pós-graduando para a complexidade da pesquisa em Humanidades no mundo contemporâneo implicará, de um lado, apreender aspectos teóricos e práticos comuns às diferentes áreas do saber. Só isto demandará todo um trabalho de integração e reflexão crítica - alimentado por esforços envidados não apenas por figuras-chave de nossa tradição intelectual mas também por grupos de pesquisadores e professores de diversas instituições na atualidade. Todavia, para obter um melhor planejamento dessa pesquisa e habilitar o pós-graduando a transitar de forma questionadora e construtiva por mais de uma área do saber, faz-se necessária, por outro lado, a adoção cuidadosa e criteriosa de alguns procedimentos, tais como os que envolvem o desenvolvimento de metodologias específicas de formação e a realização sistemática de atividades de pesquisa e debate que facultem a professores, pesquisadores e especialistas discernir e valorizar devidamente as especificidades de cada área e de cada objeto de pesquisa. É proposta do Programa adotar esses procedimentos e simultaneamente refletir sobre os mesmos, fazendo com que a pesquisa multidisciplinar, voltada à criação e à inovação, seja conduzida de modo responsável e academicamente rigoroso, em sintonia com o que vem sendo produzido em outros centros de excelência no presente. 


\section{2) Estrutura do programa}

A estrutura do Programa Multidisciplinar Culturas e Identidades Brasileiras reflete a vinculação entre as atividades de pesquisa, ensino e extensão realizadas pelos docentes do IEB, assim como a integração de seus trabalhos à área de concentração, às linhas de pesquisa e aos projetos definidos. É importante destacar que as atividades acadêmicas permanentes e qualificadas já desenvolvidas pelos docentes do IEB fundamentam a proposta do Programa. Dentre elas, pode-se destacar a consolidada prática de orientação em diversos níveis de formação acadêmica; a oferta regular de disciplinas de graduação no Instituto e de pós-graduação em diversas unidades da USP; a experiência na coordenação de pesquisas, muitas delas com expressivos financiamentos e constituindo referência para diversas áreas; os contatos e intercâmbios internacionais com outros grupos e programas de pós-graduação; e a realização de atividades artísticas e de curadoria de exposições baseadas em pesquisa original.

0 Programa encontra-se estruturado em uma única área de concentração - a área de Estudos Brasileiros - e em duas linhas de pesquisa. A primeira, intitulada "Sociedade e cultura na América Portuguesa e no Brasil", tem como proposta estudar as possibilidades de diálogo entre enfoques teóricos, metodológicos e técnicas de pesquisa em múltiplas áreas do saber, no que se refere à interpretação das relações entre sociedade e cultura na América Portuguesa e no Brasil, explorando questões em torno das mediações entre análise interna e externa de documentos de natureza histórica, geográfica, literária, artística ou outros, e da discussão de conceitos como experiência, ideologia, representação e identidade. As pesquisas realizadas pelos docentes do IEB que integram esta linha são:

1) 0 processo de urbanização do Brasil: ensino, estudos e interpretações.

2) Cidades e águas no Brasil: múltiplas abordagens.

3) Cultura e sociedade: mediações interpretativas.

4) Experiência e transformação: práticas sociais.

5) 0 Império brasileiro: política, história e cultura.

A segunda linha de pesquisa do Programa, denominada “Teorias da criação nas humanidades", propõe o estudo das teorias da criação artística, ensaística e científica, o que significa 
apreender, em enfoque teórico e metodológico multidisciplinar, o diálogo das diversas disciplinas que integram as ciências do homem, considerando a análise e a interpretação do processo criativo em fontes documentais das mesmas ciências à luz da psicanálise, da teoria literária, da crítica genética, da estética, da semiótica, da história cultural, da geografia humana, da antropologia e de outras áreas do conhecimento. As pesquisas dos docentes do IEB que pertencem a esta linha são:

1) Crítica genética e crítica literária no Brasil.

2) 0 popular e o erudito nas artes do Brasil.

3) Bibliotecas de autores e a criação nas humanidades.

4) A formação do gosto: música e política.

5) A imagem impressa do século XVIII ao século XX.

No que concerne à estrutura curricular, o Programa está organizado em torno de uma disciplina obrigatória, a ser realizada por todos os alunos no primeiro semestre do curso. Esta disciplina cumpre a função de apresentar a relação entre reflexão teórica e pesquisa documental, bem como entre estas e a diversidade e complementaridade das áreas do saber que integram o IEB e seu Programa de pós-graduação. As demais disciplinas, todas optativas, contemplam a multidisciplinaridade em seus temas, métodos, formas de avaliação e bibliografia, dividindo-se em:

a) disciplinas que, partindo de uma área especifica do saber, revelam e propõem diálogos possíveis com outros campos do conhecimento;

b) disciplinas que articulam tematicamente pelo menos duas áreas do saber, aprofundando o diálogo entre elas e especificando as trocas intelectuais possíveis.

Na proposta encaminhada, foram apresentadas quinze disciplinas optativas e uma obrigatória. São elas:

1. Análise e interpretação do Brasil (obrigatória)

2. A música brasileira do entre-guerras

3. Música e Ideologia no Brasil 
4. A emergência da identidade nacional no Brasil

5. Nação e Estado nacional como problemas historiográficos

6. No tempo de Mário de Andrade: as artes plásticas e a arquitetura no Brasil (o entre-guerras)

7. Investigações sobre a gravura brasileira do início do século XX

8. Arte e história do final do século XVIII a 1920: os viajantes no Brasil

9. A política das relações: sociabilidades de elite no Império do Brasil

10. Imaginar a nação: políticos, intelectuais e artistas na construção do Império do Brasil

11. 0 problema das mediações na análise do pensamento e da cultura

12. Cultura brasileira e estudos comparados

13. A criação de Macunaíma na biblioteca Mário de Andrade: matrizes e marginalia em uma perspectiva genética

14. Estudos de urbanização brasileira

15. 0 espaço das águas no Brasil: interpretações e representações

16. Seminários de projetos 